\title{
A NEW ALTERNATIVE SHEAR IMPROVEMENT OF CONCRETE BEAMS BY INTERNALLY REINFORCING PBO FIBER MESH
}

\author{
Sirapong SUWANPANJASIL ${ }^{1}$, Koji MATSUMOTO² and Junichiro NIWA ${ }^{3}$ \\ ${ }^{1}$ Member of JSCE, Ph.D. Candidate, Dept. of Civil Eng., Tokyo Institute of Technology \\ (2-12-1-M1-17 O-okayama, Meguro-ku, Tokyo 152-8552, Japan) \\ E-mail: suwanpanjasil.s.aa@m.titech.ac.jp \\ 2Member of JSCE, Project Assistant Professor, Institute of Industrial Science, The University of Tokyo \\ (4-6-1 Komaba, Meguro-ku, Tokyo 153-8505, Japan) \\ E-mail: km312@iis.u-tokyo.ac.jp \\ ${ }^{3}$ Fellow of JSCE, Professor, Dept. of Civil Eng., Tokyo Institute of Technology \\ (2-12-1-M1-17 O-okayama, Meguro-ku, Tokyo 152-8552, Japan) \\ E-mail: jniwa@cv.titech.ac.jp
}

\begin{abstract}
This paper aims to develop a new method for shear reinforcing concrete beams by using the ultrahigh performance $\mathrm{PBO}$ fiber mesh as a replacement for conventional stirrups inside a concrete structural member. The elementary test was performed first to investigate the general behavior of the internal reinforcing PBO fiber mesh as a fundamental objective of this study. Then, nine RC beams with and without internal PBO fiber mesh were conducted in the RC beam test. The parameters in the RC beam test were the number of internal PBO mesh layers, the width of internal PBO mesh in the shear span, and the reinforcing configuration of the internal PBO mesh. The experimental results showed that the shear capacity and the shear carried by internal PBO fiber mesh increased significantly with a higher number of the internal mesh layers; however, the shear capacity decreased when the width of internal mesh in the shear span was expanded. Besides, the difference in reinforcing configuration of the internal PBO mesh showed a great impact on the shear capacity of concrete beams reinforced with internal PBO fiber mesh. Furthermore, an empirical method for evaluating shear carried by internal PBO fiber mesh was modeled and a moderate agreement between values from the model and values from the experiment was obtained.
\end{abstract}

Key Words : PBO fiber mesh, internal reinforcing, shear capacity, shear carried by fiber mesh

\section{INTRODUCTION}

It has been a long time since a number of stirrups have been used to strengthen reinforced concrete (RC) members since the shear failure exhibits a sudden and brittle behavior, leading to loss of life and property. Although the utilization of stirrups improves the shear performance of RC members, it still shows some drawbacks because of the electromagnetic property of the steel stirrups causing the corrosion damage inside RC structures. In recent years, the scope of study about shear improvement of RC members has expanded to the application of Fiber Reinforced Polymer (FRP), especially for the continuous FRP sheets such as Carbon and Glass FRP (CFRP and GFRP) sheets. Many researches have been conducted to confirm the ability of the FRP sheets to externally strengthen the RC members in shear ${ }^{1)-3)}$. In addition, the calculation for design shear contribution due to continuous FRP sheets is now available in the recommendations of the Japan Society of Civil Engineers (JSCE) ${ }^{4}$.

At present, one of the newly developed FRP materials, called Polyparaphenylene Benzobis Oxazole (PBO) fiber mesh, is being adopted to improve the performance of existing RC structures both in flexure and shear. A sample of the PBO fiber mesh is presented in Fig. 1. In fact, the mechanical properties of the PBO fibers are remarkable since the elastic modulus of $270 \mathrm{kN} / \mathrm{mm}^{2}$ and the tensile strength of $5800 \mathrm{~N} / \mathrm{mm}^{2}$ are both fairly higher than the high-strength type of carbon fibers. They also demonstrate great impact tolerance, high energy absorption, high creep as well as fire resistance ${ }^{5)}$.

Many recent studies about the PBO fiber mesh have been performed by using the PBO fiber mesh 
together with the Fiber Reinforced Cementitious Mortars (FRCM) system. FRCM is the alternative bonding system of replacing the conventional organic resin with inorganic ones so that some disadvantages such as the lack of fire resistance, degradation under ultraviolet (UV) light, and low compatibility with the substrate material can be eliminated ${ }^{6)}$. The available test results have shown a good performance in the application of the PBO-FRCM system. Ombres ${ }^{7)}$ reported that the PBO-FRCM system can improve the flexural capacity of the strengthened RC beams from $10 \%$ to $44 \%$ with respect to the value relative to the unstrengthened beams. The effectiveness of the PBO-FRCM system for shear strengthening was proved by Di Tommasso et al. ${ }^{8)}$. They concluded that the Carbon-FRCM system was less effective than the PBO-FRCM system.

This present research attempts to create a new innovation in shear improvement of RC members by using the PBO fiber mesh for reinforcement inside the RC beams as a replacement for the conventional stirrups. In fact, this research can be considered as an original study of the structural concrete members internally reinforced with FRP mesh. This new method is expected to overcome the disadvantage of utilizing stirrups and obtain the same merits of the FRCM system as mentioned before; however, additional inorganic resin is not necessary in this developing method resulting in cost reduction and speed of application. Moreover, the internal reinforcing mesh can be applied to the concrete members in all preferred shapes without any pre-bending like in conventional stirrups or stainless bars.

The main objective of this research is to investigate the mechanical characteristic of the concrete beams reinforced with internal PBO fiber mesh failing in shear. The contents of this paper can be divided into two parts. First is the elementary test in which small six concrete specimens are tested in order to ensure the reinforcing performance of the PBO fiber mesh when they are used inside concrete cover. Second is the RC beam test in which nine RC beams varying in the number of PBO fiber mesh layers, the width of PBO mesh in the shear span, and the reinforcing configuration are conducted. The

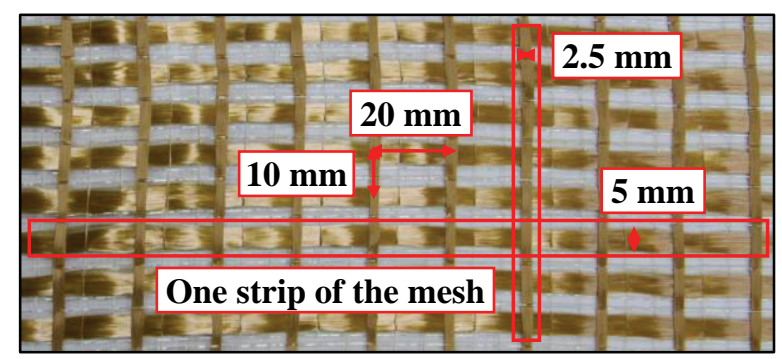

Fig. 1 PBO fiber mesh. shear capacity, shear carried by internal PBO fiber mesh, load-displacement relationship, shear resisting mechanism and crack pattern are presented and discussed in this paper. Finally, the model for evaluating shear carried by internal PBO fiber mesh shall be proposed and the reinforcing efficiency compared with the equation for evaluating shear carried by conventional continuous CFRP sheets from the JSCE recommendations.

\section{ELEMENTARY TEST}

Because the application of PBO fiber mesh for reinforcement inside concrete members has never been verified by any research yet, the elementary test is conducted in order to investigate the internal reinforcing mechanism of the PBO fiber mesh as a fundamental objective of this study. This test mainly aims to obtain the actual tensile strength of the PBO fiber mesh when it is used as a reinforcing material inside concrete members and to verify whether this internal reinforcing method may be applied in bigger structural elements or not.

\section{(1) Test programs and specimen details}

The elementary test consisted of six concrete specimens varying in the number of layers of reinforcing mesh and the epoxy resin coating method. All reinforced specimens had the effective depth $(d)$ of $72.5 \mathrm{~mm}$, width $(b)$ of $100 \mathrm{~mm}$, height $(h)$ of $100 \mathrm{~mm}$ and total length $(l)$ of $400 \mathrm{~mm}$ with $150 \mathrm{~mm}$ of the

Table 1 Elementary test programs.

\begin{tabular}{c|c|c|c|c}
\hline $\begin{array}{c}\text { Specimen } \\
\text { designation }\end{array}$ & $\begin{array}{c}\text { Number of } \\
\text { PBO mesh } \\
\text { layers }\end{array}$ & $\begin{array}{c}\text { Number of } \\
\text { PBO mesh } \\
\text { strips }\end{array}$ & $\begin{array}{c}A_{f} \\
\left(\mathrm{~mm}^{2}\right)\end{array}$ & $\begin{array}{c}\text { Epoxy } \\
\text { resin } \\
\text { coating }\end{array}$ \\
\hline REF1 & - & - & - & - \\
\hline REF2 & - & - & - & - \\
\hline Uncoated L1 & 1 & 7 & 1.59 & uncoated \\
\hline Coated L1 & 1 & 7 & 1.59 & coated \\
\hline Coated L2 & 2 & 14 & 3.19 & coated \\
\hline Coated L3 & 3 & 21 & 4.78 & coated \\
\hline
\end{tabular}

$A_{f}=$ total cross-sectional area of the PBO fiber mesh

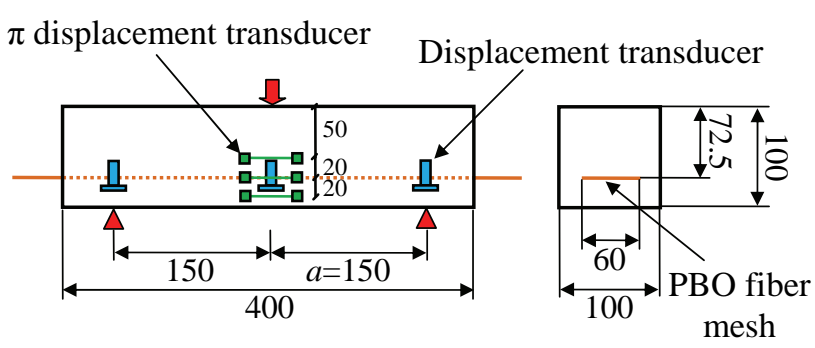

Fig. 2 Details of specimens in elementary test (unit: mm). 
shear span. The summary of test programs and details of the specimens are illustrated in Table $\mathbf{1}$ and Fig. 2, respectively.

In the programs, REF1 and REF2 were determined as the reference specimens in which no reinforcing material was provided. The Uncoated L1 is the specimen with one layer of the reinforcing PBO fiber mesh arranged inside the specimen with $27.5 \mathrm{~mm}$ of concrete cover; however, the epoxy resin was not applied to the mesh in this specimen. In the case of Coated L1, the number of reinforcing mesh was still one layer, but the mesh was coated with epoxy resin before casting concrete. Coated PBO fiber mesh was also used in Coated L2 and Coated L3, but the number of layers was increased to two and three layers, respectively.

\section{(2) Materials used in elementary test a) Concrete}

According to the previous study by $\mathrm{Li} \& \mathrm{Xu}^{9}$, the concrete used for textile reinforcements (the textiles with rovings made of fiber-threads through basketry which are oriented parallel with the occurring stresses) should be self-compacting concrete (SCC) having a very nice workability and consistency. This is to ensure that the matrix can fully penetrate the textile without segregation, to strengthen the bond between fiber and matrix. Therefore, the SCC with high flowability was used in this study. The mix proportions of the SCC, as shown in Table 2, included high-early strength cement, limestone powder, fine aggregates, coarse aggregates with $15 \mathrm{~mm}$ maximum size, superplasticizer (high-performance air entrained water-reducing agent) and viscosity improver. The designed compressive strength of 7-day curing age was $35 \mathrm{~N} / \mathrm{mm}^{2}$.

\section{b) PBO fiber mesh}

The two orthogonal PBO fiber meshes used in the elementary test and the RC beam test were produced by roving PBO fibers in one strip of the main direction $5 \mathrm{~mm}$ in width and $0.0455 \mathrm{~mm}$ nominal thickness. However, the weaker direction of the mesh was $2.5 \mathrm{~mm}$ in width and $0.0115 \mathrm{~mm}$ nominal thickness for each strip ${ }^{10)}$.

All reinforcing PBO fiber mesh in the elementary test had a total length of $600 \mathrm{~mm}$ and total width of 60 $\mathrm{mm}$. Therefore, there were $20 \mathrm{~mm}$ left in each side of the formwork to allow coarse aggregates to penetrate underneath the mesh. The coated PBO fiber mesh was thoroughly coated with epoxy resin and moved to the formworks around 2 hours before casting concrete.

\section{c) Epoxy resin}

The PBO fiber meshes used in Coated L1, Coated L2, and Coated L3 were thoroughly coated with epoxy resin in order to uniformly gather the small fibers in the mesh, leading to a higher performance of the reinforcing system. The epoxy resin used in this study had a tensile strength higher than $30 \mathrm{~N} / \mathrm{mm}^{2}$ based on the JIS K 7161 standard.

\section{(3) Loading method and measurements}

The specimens were subjected to a three-point bending test with the load generated from the loading machine at the loading rate about $0.1 \mathrm{~mm} / \mathrm{min}$ until the failure of specimens. The specimens were placed on the roller supports to satisfy the simply supported condition.

The results were monitored in terms of applied load and mid-span displacement and the crack propagation on the side surface was recorded by taking pictures during the test. For the calculation of actual tensile strength of the mesh, the measurement of crack width was made by three $\pi$ displacement transducers, attached to the side surface of the specimens at the level of $50 \mathrm{~mm}, 70 \mathrm{~mm}$, and $90 \mathrm{~mm}$ from the top of the specimens as shown in Fig. 2.

\section{(4) Test results of elementary test}

\section{a) Load-displacement relationships and failure modes}

Figure 3 shows the load and mid-span displacement relationships of all specimens in the elementary test. It can be seen that the loads of the two reference specimens (REF1 and REF2) linearly increased until the flexural crack occurred at $11.0 \mathrm{kN}$ in REF1 and $10.5 \mathrm{kN}$ in REF2. After that, the load suddenly dropped to almost $0 \mathrm{kN}$. The failure of these reference specimens is shown in Fig. 4.

For the reinforced specimens, all specimens demonstrated a similar behavior at the initial stage, in which the load linearly increased until the flexural crack happened close to the center of the specimens. The loads, at the stage when the flexural crack hap-

Table 2 Mix proportions of concrete.

\begin{tabular}{|c|c|c|c|c|c|c|c|c|c|}
\hline \multirow{2}{*}{$\begin{array}{c}\text { Maximum size } \\
\text { of coarse } \\
\text { aggregate } \\
(\mathrm{mm})\end{array}$} & \multirow{2}{*}{$\begin{array}{c}\text { Water } \\
\text { cement } \\
\text { ratio } \\
(\%)\end{array}$} & \multirow{2}{*}{$\begin{array}{c}\text { Sand } \\
\text { aggregate } \\
\text { ratio } \\
(\%) \\
\end{array}$} & \multicolumn{7}{|c|}{ Unit weight $\left(\mathrm{kg} / \mathrm{m}^{3}\right)$} \\
\hline & & & Water & Cement & $\begin{array}{c}\text { Limestone } \\
\text { powder }\end{array}$ & $\begin{array}{c}\text { Fine ag- } \\
\text { gregate }\end{array}$ & $\begin{array}{c}\text { Coarse } \\
\text { aggregate }\end{array}$ & Superplasticizer & $\begin{array}{l}\text { Viscosity } \\
\text { improver } \\
\end{array}$ \\
\hline 15 & 60 & 45 & 175 & 292 & 249 & 718 & 857 & 8.12 & 0.35 \\
\hline
\end{tabular}




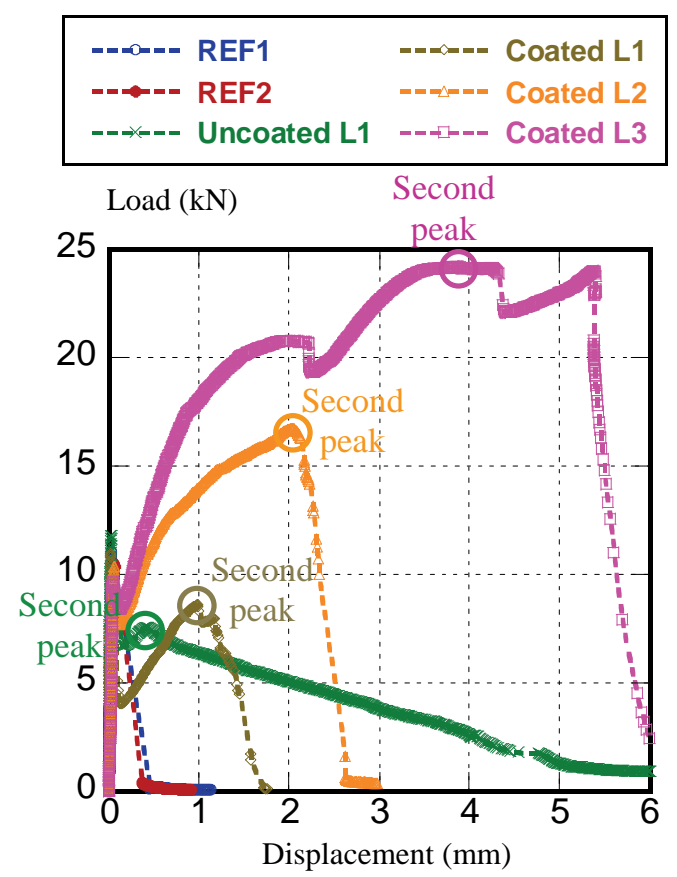

Fig. 3 Load-displacement curves of elementary test.

Table 3 Summary of elementary test results.

\begin{tabular}{|c|c|c|c|c|c|}
\hline \multirow{2}{*}{$\begin{array}{l}\text { Specimen } \\
\text { designation }\end{array}$} & \multicolumn{3}{|c|}{$\begin{array}{l}\text { Mechanical properties } \\
\text { of concrete }\end{array}$} & \multirow{2}{*}{$\begin{array}{c}\text { Load at } \\
\text { flexural } \\
\text { crack } \\
(\mathrm{kN})\end{array}$} & \multirow{2}{*}{$\begin{array}{c}\text { Load at } \\
\text { second } \\
\text { peak } \\
(\mathrm{kN})\end{array}$} \\
\hline & $\begin{array}{c}f_{c}^{\prime} \\
\left(\mathrm{N} / \mathrm{mm}^{2}\right)\end{array}$ & $\begin{array}{c}f_{t} \\
\left(\mathrm{~N} / \mathrm{mm}^{2}\right)\end{array}$ & $\begin{array}{c}E_{c} \\
\left(\mathrm{kN} / \mathrm{mm}^{2}\right)\end{array}$ & & \\
\hline REF1 & 36.3 & 2.94 & 31.3 & 11.0 & - \\
\hline REF2 & 36.3 & 2.94 & 31.3 & 10.5 & - \\
\hline Uncoated L1 & 36.3 & 2.94 & 31.3 & 11.9 & 7.6 \\
\hline Coated L1 & 36.3 & 2.94 & 31.3 & 11.0 & 8.6 \\
\hline Coated L2 & 39.5 & 2.47 & 28.9 & 10.4 & 16.7 \\
\hline Coated L3 & 39.5 & 2.47 & 28.9 & 9.7 & 24.2 \\
\hline
\end{tabular}

$f_{c}^{\prime}=$ compressive strength, $f_{t}=$ tensile strength, $E_{c}=$ Young's modulus

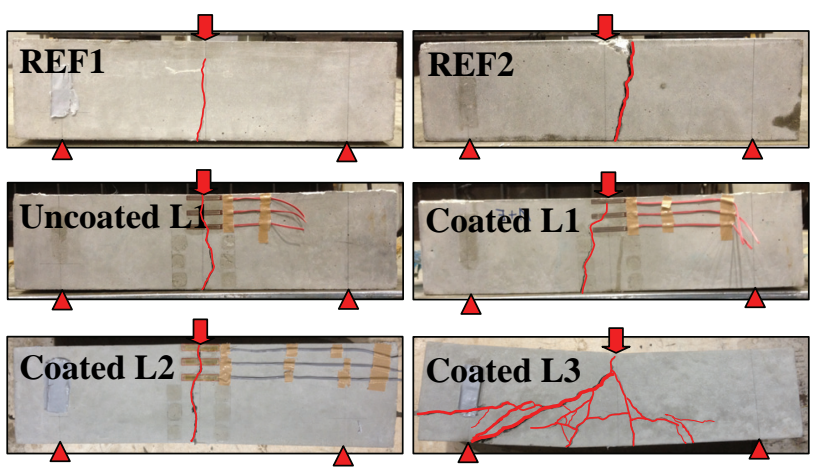

Fig. 4 Crack patterns of specimens in elementary test.
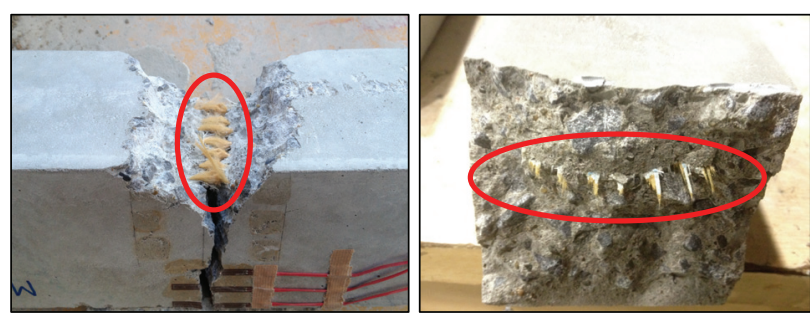

Fig. 5 Detachment of PBO fibers. Fig. 6 Rupture of PBO mesh. pens, are indicated as "Load at flexural crack" in Table 3. The loads then dropped slightly and in creased again owing to the internal reinforcing PBO fiber mesh. This second increase led to the second peak loads that are indicated as "Load at second peak" in Table 3 and will be discussed again in the next section. In addition, the second peak loads were used to calculate the actual tensile strength of the mesh since they could represent the reinforcing ability of the internal mesh at the failure stage.

In Uncoated L1, after the initiation of the flexural crack, the load reached the second peak load at 7.6 $\mathrm{kN}$ and then decreased gradually with much extension in displacement as shown in the green line in Fig. 3. The failure mode of this specimen was considered as the detachment of PBO fibers in the mesh as shown in Fig. 5.

The same behavior as that of the Uncoated L1 was found in Coated L1; however, a higher second peak load at $8.6 \mathrm{kN}$ could be obtained and the extension in displacement was not observed in Coated L1. This meant that the internal reinforcing PBO fiber mesh that was coated with epoxy resin before casting concrete could result in a higher performance than the uncoated one in terms of tensile load at the failure stage. The failure mode of Coated L1 was a rupture of the mesh as shown in Fig. 6.

In Coated L2, as the internal mesh layer was increased to two layers, the second peak load of Coated L2 was almost twice as that of Coated L1 at $16.7 \mathrm{kN}$. The failure mode of this specimen was also a rupture of the PBO fiber mesh.

In the case of Coated L3, after the load reached its flexural cracking load at $9.7 \mathrm{kN}$, it dropped slightly and increased again due to the reinforcing mesh. During this stage, some cracks propagated along the mesh alignment in the horizontal direction of the concrete surface even though the load still increased continuously. Finally, a big diagonal crack occured sharply and the load immediately dropped at the highest load of $24.2 \mathrm{kN}$. Therefore, the failure mode of Coated L3 was considered as a shear failure as shown in Fig. 4.

\section{b) Increase of the second peak load}

As mentioned before, the load of the specimens reinforced by PBO fiber mesh showed a second peak load after the occurrence of flexural crack while the loads of REF1 and REF2 did not rebound after the first peak load.

The comparison of the second peak load, as shown in Table 3, reveals that the increase in the number of internal PBO fiber mesh layers can increase the second peak load significantly. The second peak loads of Coated L2 and Coated L3 are higher than Coated L1 by about $94.2 \%$ and $181.4 \%$, respectively. 


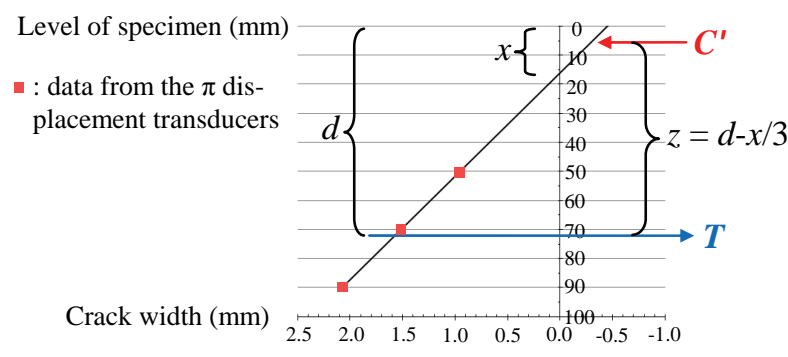

Fig. 7 Calculation method for $z$.

Besides, the comparison of the second peak load between Coated L1 and Uncoated L1 showed that the efficiency of the reinforcing mesh could be increased if the mesh was coated with epoxy resin before casting concrete because the fibers were assembled into a group and had better stiffness resulting in the increase of the second peak load of Coated L1 by about $13.6 \%$ when compared with Uncoated L1.

\section{c) Actual tensile strength of PBO fiber mesh}

The actual tensile strength of the PBO mesh $\left(f_{p}\right)$ was calculated by considering the bending moment of the reinforced specimens at the second peak load $(M)$ and divided by the product of total cross sectional area of the mesh $\left(A_{f}\right)$ multiplied by moment arm $(z)$ as shown in Eq. (1):

$$
f_{p}=\frac{M}{A_{f} \cdot z}
$$

The moment arm ( $z$ ) can be defined as explained in Fig. 7. The effective depth $(d)$ of the specimens was equal to $72.5 \mathrm{~mm}$. The depth of the compression zone (defined as $x$ in Fig. 7) was obtained from the distribution of the crack width at the second peak load of each specimen (data from the $\pi$ displacement transducers). The actual tensile strength of the mesh in each specimen was compared with the maximum tensile strength of the PBO fiber mesh indicated by the manufacturer ${ }^{10)}$, which was equal to $5800 \mathrm{~N} / \mathrm{mm}^{2}$.

From Eq. (1), the actual tensile strength was equal to $4911 \mathrm{~N} / \mathrm{mm}^{2}$ in Uncoated L1, $5580 \mathrm{~N} / \mathrm{mm}^{2}$ in Coated L1, $5606 \mathrm{~N} / \mathrm{mm}^{2}$ in Coated L2, and 5656 $\mathrm{N} / \mathrm{mm}^{2}$ in Coated L3. The difference between the actual tensile strength from the calculation and the value of $5800 \mathrm{~N} / \mathrm{mm}^{2}$ indicated by the manufacturer was $15.3 \%$ for Uncoated L1, 3.8\% for Coated L1, $3.3 \%$ for Coated L2, and 2.5\% for Coated L3. It was remarkable that the three layers of reinforcing mesh in Coated L3 demonstrated very close tensile strength to the value of $5800 \mathrm{~N} / \mathrm{mm}^{2}$ even if the failure mode of this specimen was a shear failure and not a rupture of the mesh.

The results implied that the internal reinforcing PBO fiber mesh could be at almost the same level as its maximum tensile strength, especially since the
Table 4 Experimental cases in RC beam test.

\begin{tabular}{c|c|c|c|c|c}
\hline \multirow{2}{*}{ Series } & $\begin{array}{c}\text { Specimen } \\
\text { designation }\end{array}$ & $\begin{array}{c}\text { Number } \\
\text { of PBO } \\
\text { fiber } \\
\text { mesh } \\
\text { layers }\end{array}$ & $\begin{array}{c}L_{f} \\
(\mathrm{~mm})\end{array}$ & $\begin{array}{c}\text { Number } \\
\text { of PBO } \\
\text { fiber } \\
\text { mesh } \\
\text { strips }\end{array}$ & $\begin{array}{c}A_{f} \\
\left(\mathrm{~mm}^{2}\right)\end{array}$ \\
\hline I & REF & - & - & - & - \\
\hline I, II & PBO3-700 & 3 & 700 & 225 & 102.4 \\
\hline I & PBO2-700 & 2 & 700 & 150 & 68.3 \\
\hline I, II & PBO1-700 & 1 & 700 & 75 & 34.1 \\
\hline \multirow{2}{*}{ II } & PBO1-560 & 1 & 560 & 60 & 27.3 \\
\cline { 2 - 6 } & PBO1-420 & 1 & 420 & 45 & 20.5 \\
\hline I, II, III & PBO1-280 & 1 & 280 & 30 & 13.7 \\
\hline I, II & PBO3-280 & 3 & 280 & 90 & 41.0 \\
\hline III & PBO1-280s & 1 & $2 \times 140$ & $2 \times 15$ & 13.7 \\
\hline
\end{tabular}

$L_{f}=$ width of the internal PBO fiber mesh in shear span

$A_{f}=$ total cross-section area of PBO fiber mesh (2 side)

mesh was coated with epoxy resin before casting concrete. Besides, the three-point loading test performed in the elementary test was reliable and sufficient for this study because the reasonable values of the results were obtained. Moreover, the results from the elementary test also proved that this internal reinforcing method was effective and can be applied to bigger concrete structural element in a further study.

\section{EXPERIMENTAL PROGRAM OF RC BEAM TEST}

\section{(1) Experimental cases and details of specimens}

The experimental cases in the RC beam test consisted of nine RC beams that could be categorized into three series as summarized in Table 4. Each reinforced specimen was designated based on the type of mesh (PBO) following the number of mesh layers, the width of the meshes $\left(L_{f}\right.$ in Fig. 8), and the reinforcing configuration of the internal PBO fiber mesh.

In Series I, the effect of the number of internal PBO fiber mesh layers was considered. REF was the reference beam in which the beam was not reinforced in shear by any mesh or stirrup. The number of mesh layers was increased from zero layer in REF to one, two, and three layers in PBO1-700, PBO2-700, and PBO3-700, respectively, with the same width of the mesh of $700 \mathrm{~mm}$. Moreover, the different number of mesh layers between PBO1-280 and PBO3-280 with the same width of the mesh of $280 \mathrm{~mm}$ was compared in this series as well.

In Series II, the number of mesh layers was constant; however, the width of internal mesh was reduced from $700 \mathrm{~mm}$ in PBO1-700 to $560 \mathrm{~mm}, 420$ 


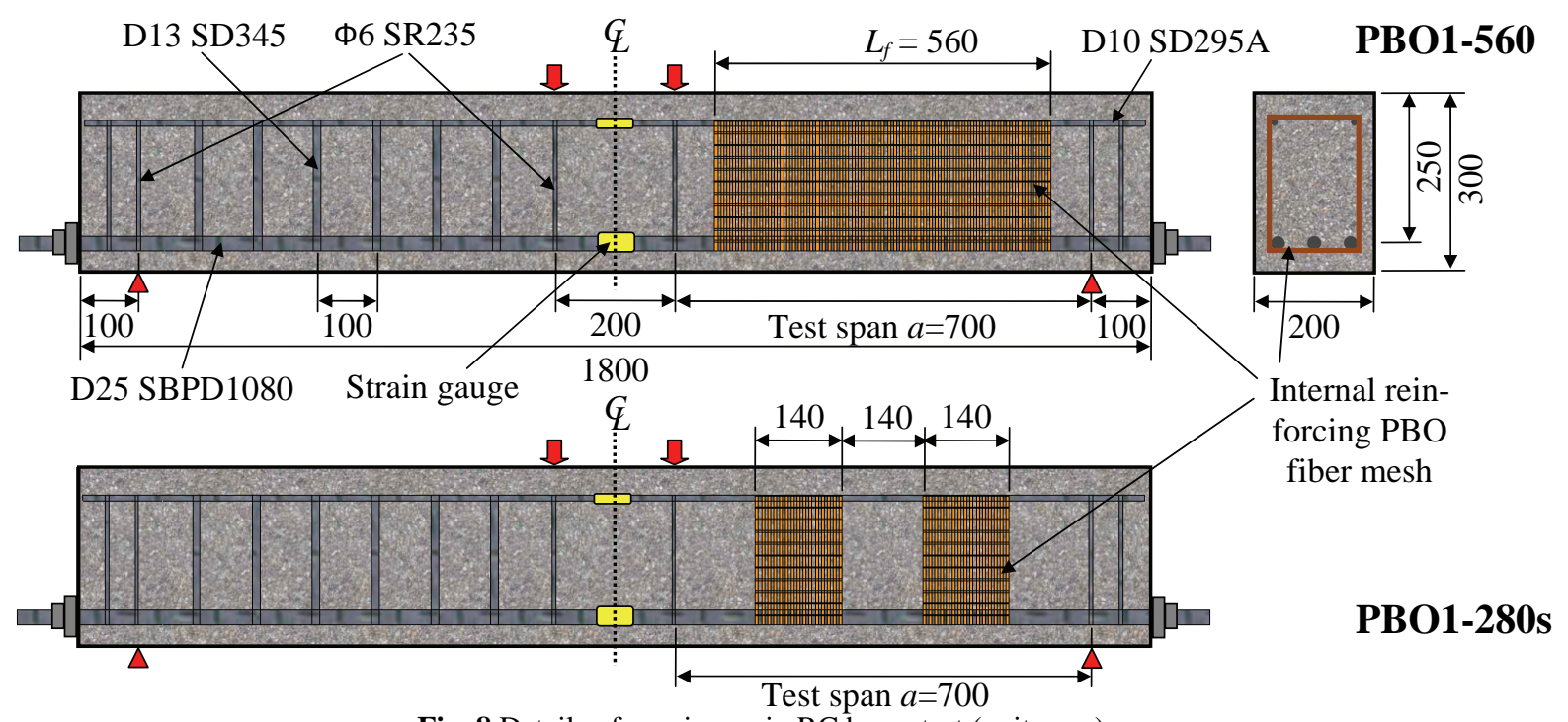

Fig. 8 Details of specimens in RC beam test (unit: $\mathrm{mm}$ ).

$\mathrm{mm}$, and $280 \mathrm{~mm}$ in PBO1-560, PBO1-420, and PBO1-280, respectively. In addition, the comparison between PBO3-700 and PBO3-280 was also determined in this series as the width of PBO fiber mesh was changed but the number of layers was the same.

The investigation of the reinforcing configuration of the mesh between PBO1-280 and PBO1-280s was examined in Series III. In PBO1-280, the beam was reinforced by one layer of $280 \mathrm{~mm}$ PBO fiber mesh at the center of the shear span. On the other hand, the mesh provided in $\mathrm{PBO} 1-280$ s was divided into two sections of $140 \mathrm{~mm}$ each and was not set at the center of the shear span as shown in Fig. 8. It must be noted that even if a number of experiments about the wrapping method with spacing and intervals of the FRP sheet had been conducted in many papers such as that by Khalifa \& $\mathrm{Nanni}^{1)}$ or Zhang \& $\mathrm{Hsu}^{2)}$, the purpose of this study is different from these authors since their researches did not consider the same amount of the separated and unseparated sheet as the authors of this current study did.

All specimens were designed to fail in shear at the test shear span; therefore, a number of stirrups were provided in the untested shear span and deformed high-strength reinforcing bars were arranged as tensile reinforcing bars with the longitudinal reinforcement ratio $\left(p_{v}\right)$ of $3.04 \%$ as shown in the details of specimens in Fig. 8. The shear span (a) was 700 $\mathrm{mm}$, the width of specimens $(b)$ was $200 \mathrm{~mm}$, the height of specimens $(h)$ was $300 \mathrm{~mm}$, and the shear span effective depth ratio (a/d) was 2.8.

\section{(2) Materials used in RC beam test a) Concrete}

The concrete used in the RC beam test had the same mix proportion as the concrete used in the elementary test. The designed compressive strength of 7-day curing age was also $35 \mathrm{~N} / \mathrm{mm}^{2}$.

\section{b) Steel reinforcement}

The arrangement of steel reinforcements is illustrated in Fig. 8. Three deformed high-strength reinforcing bars with 25.4-mm nominal diameter $\left(A_{s}=507.7 \mathrm{~mm}^{2}\right)$ and $1181 \mathrm{~N} / \mathrm{mm}^{2}$ yield strength were arranged as tensile reinforcing bars. The stirrups in the untested shear span had 12.7-mm nominal diameter $\left(A_{s}=126.7 \mathrm{~mm}^{2}\right)$ with spacing of $100 \mathrm{~mm}$ and the yield strength was $388 \mathrm{~N} / \mathrm{mm}^{2}$. Two $9.53-\mathrm{mm}$ nominal diameter deformed bars $\left(A_{s}=71.3 \mathrm{~mm}^{2}\right)$ were selected as the compression bars with yield strength of $388 \mathrm{~N} / \mathrm{mm}^{2}$. In addition, round bars with 6-mm diameter $\left(A_{s}=28.3 \mathrm{~mm}^{2}\right)$ with yield strength of 309 $\mathrm{N} / \mathrm{mm}^{2}$ were provided to prevent failure at the point load in all specimens.

\section{c) PBO fiber mesh}

The total length of reinforcing PBO fiber mesh wrapped around the steel reinforcements in PBO1-700, PBO1-560, PBO1-420, PBO1-280, and PBO1-280s was about $0.9 \mathrm{~m}$, while the total length of reinforcing mesh was increased to about $1.6 \mathrm{~m}$ in PBO2-700 and about $2.3 \mathrm{~m}$ in PBO3-700 and PBO3-280.

\section{d) Epoxy resin}

In the RC beam test, all reinforcing PBO fiber meshes were coated with epoxy resin used in the elementary test before casting concrete, since the results from the elementary test revealed that the coated PBO fiber mesh could result in higher reinforcing performance than that of the uncoated one. In the reinforced specimens, the epoxy resin was used to coat the mesh approximately $570 \mathrm{~g} / \mathrm{m}^{2}$ and the mesh was coated around 2 hours before casting concrete.

\section{(3) Fabrication of the specimens}

After the arrangement of steel reinforcements, the PBO fiber mesh was attached to the compression bar as a beginning point by using a glue-sticky epoxy 


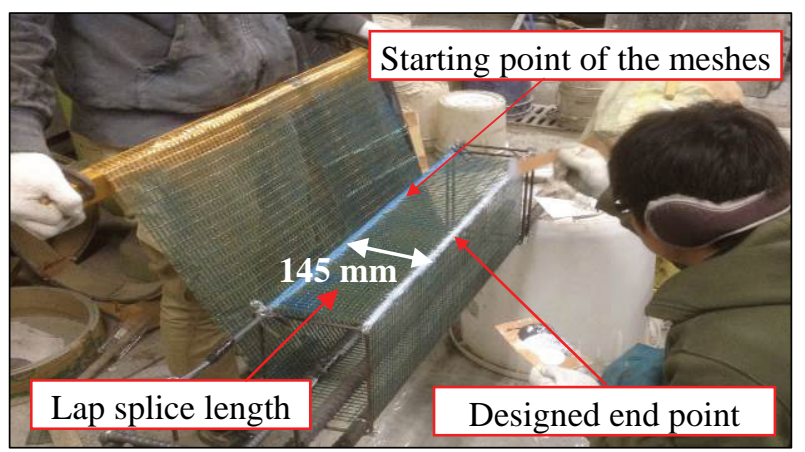

Fig. 9 Fabrication of the PBO fiber meshes.

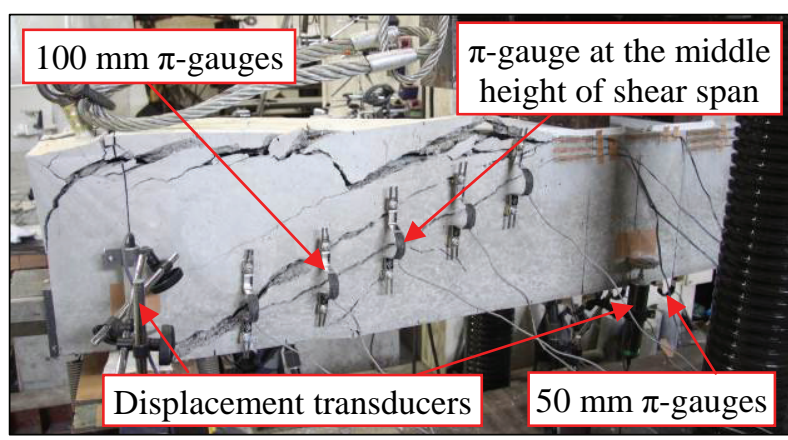

Fig. 10 Measurement items.

resin that could rapidly harden. Then, the mesh was thoroughly coated with epoxy resin. After that, the PBO fiber mesh was wrapped around compression bars and tension bars until it reached the designed end point. It was then fixed by a glue-sticky epoxy resin again. Therefore, there was the $145 \mathrm{~mm}$ lap splice length to ensure the anchorage of the PBO fiber mesh as shown in Fig. 9. Additionally, the PBO fiber mesh was always kept tensioned by hand during the wrapping process in order to ensure the highest efficiency of the reinforcing system.

The SCC was then poured into the formwork. Because of the high flowability of the SCC, the fresh concrete flowed inside the wrapping PBO fiber mesh easily without additional compacting.

\section{(4) Loading method}

The specimens were subjected to a four-point bending and the load generated from a $2000-\mathrm{kN}$ loading machine. Teflon sheets and grease were inserted between the roller supports and specimens to prevent friction in horizontal direction. To reduce the stress concentration at the loading point, steel plates and a load distribution beam were placed. In addition, anchorage plates and nuts were locked to the longitudinal reinforcing bars to prevent anchorage failure at the tips of all specimens during the loading test.

\section{(5) Measurements}

Mid-span displacement of the specimens was measured by four displacement transducers set up at mid-span and supporting points. The crack opening width of diagonal cracks was measured by $100 \mathrm{~mm}$ $\pi$-gauges attached on the side surface along the diagonal crack path. The crack opening width of flexural cracks was measured by $50 \mathrm{~mm} \pi$-gauges attached at the bottom of the specimens as shown in Fig. 10. The crack propagation on the side surface was recorded by taking pictures during the loading test as well. In addition, the yielding of the tensile reinforcing bars was checked by the $2 \mathrm{~mm}$ gauge length of electrical strain gauges attached at the center of the bars.

\section{RESULTS AND DISCUSSION OF RC BEAM TEST}

\section{(1) Shear capacities in RC beam test}

a) Calculation method of shear carried by internal PBO fiber mesh

In this study, the shear capacity of the reinforced specimens was assumed to be a summation of shear carried by concrete and the internal PBO fiber mesh as expressed in Eq. (2). The shear carried by concrete was formulated from the shear capacity of the reference ( $V_{\text {exp_REF }}$ ) multiplied by the variation in compressive strength of concrete between the reference and the other specimens as shown in Eq. (3). The third root was applied in Eq. (3) because the shear strength was proportional to the third root of the compressive strength of concrete according to the equation of RC beams without shear reinforcement as proposed by Niwa et al. ${ }^{11)}$.

$$
\begin{gathered}
V=V_{c}+V_{f} \\
V_{c}=V_{c_{-} R E F} \cdot\left(f_{c}^{\prime} / f_{c_{-} R E F}^{\prime}\right)^{1 / 3}
\end{gathered}
$$

where $V$ is the shear capacity of RC beams reinforced with internal PBO fiber mesh $(\mathrm{N}), V_{c}$ is the shear carried by concrete of the specimen considered $(\mathrm{N})$, $V_{f}$ is the shear carried by internal PBO fiber mesh $(\mathrm{N}), V_{C_{-} R E F}$ is the shear capacity of the reference specimen $(\mathrm{N}), f_{c}^{\prime}$ is the compressive strength of concrete of the specimen considered $\left(\mathrm{N} / \mathrm{mm}^{2}\right)$, and $f_{{ }_{C} R E F}^{\prime}$ is the compressive strength of concrete of the reference specimen $\left(\mathrm{N} / \mathrm{mm}^{2}\right)$.

Thus, the experimental value of the shear carried by internal PBO fiber mesh can be expressed as follows:

$$
V_{\text {fexp }}=V_{\text {exp }}-V_{c}
$$

where $V_{\text {fexp }}$ is the experimental value of shear carried 
Table 5 Summary of RC beam test results.

\begin{tabular}{|c|c|c|c|c|c|c|}
\hline \multirow{2}{*}{$\begin{array}{l}\text { Specimen } \\
\text { designation }\end{array}$} & \multicolumn{2}{|c|}{$\begin{array}{c}\text { Mechanical } \\
\text { properties } \\
\text { of concrete }\end{array}$} & \multirow{2}{*}{$\begin{array}{c}V_{\text {exp }} \\
(\mathrm{kN})\end{array}$} & \multirow{2}{*}{$\begin{array}{c}V_{c} \\
(\mathrm{kN})\end{array}$} & \multirow{2}{*}{$\begin{array}{l}V_{\text {fexp }} \\
(\mathrm{kN})\end{array}$} & \multirow[t]{2}{*}{ Failure mode } \\
\hline & $\begin{array}{c}f_{c}^{\prime} \\
\left(\mathrm{N} / \mathrm{mm}^{2}\right)\end{array}$ & $\begin{array}{c}E_{c} \\
\left(\mathrm{kN} / \mathrm{mm}^{2}\right)\end{array}$ & & & & \\
\hline REF & 41.2 & 30.0 & 77.8 & 77.8 & - & Diagonal tension \\
\hline PBO3-700 & 38.9 & 29.4 & 166.4 & 76.3 & 90.1 & Shear failure (Horizontal crack and PBO mesh rupture) \\
\hline PBO2-700 & 33.8 & 28.3 & 134.3 & 72.8 & 61.5 & Shear failure (Horizontal crack and PBO mesh rupture) \\
\hline PBO1-700 & 40.3 & 31.5 & 115.8 & 77.2 & 38.6 & Shear failure (Horizontal crack and PBO mesh rupture) \\
\hline PBO1-560 & 39.8 & 30.5 & 130.5 & 76.9 & 53.6 & Shear failure (Horizontal crack and PBO mesh rupture) \\
\hline PBO1-420 & 38.3 & 29.5 & 130.7 & 75.9 & 54.8 & Shear failure (Horizontal crack and PBO mesh rupture) \\
\hline PBO1-280 & 34.0 & 27.6 & 141.5 & 73.0 & 68.5 & Shear failure (PBO mesh rupture) \\
\hline PBO3-280 & 34.2 & 27.7 & 172.8 & 73.1 & 99.7 & Shear failure (Horizontal crack and PBO mesh rupture) \\
\hline PBO1-280s & 38.4 & 28.1 & 100.6 & 76.0 & 24.6 & Shear failure (PBO mesh rupture) \\
\hline
\end{tabular}

$f_{c}^{\prime}=$ compressive strength, $E_{c}=$ Young's modulus, $V_{\text {exp }}=$ experimental values of shear capacity, $V_{c}=$ shear carried by concrete, $V_{\text {fexp }}=$ experimental values of shear carried by internal PBO mesh

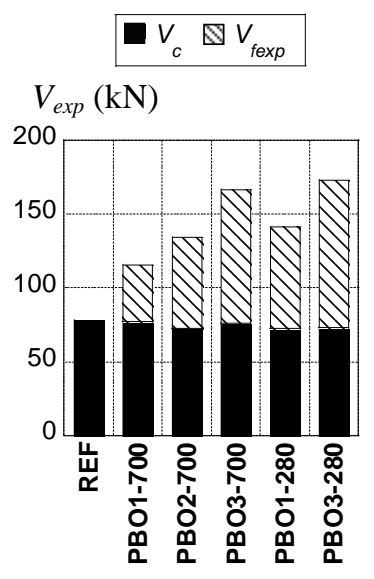

Specimen designation

Fig. 11 Shear contributions of specimens in Series I.

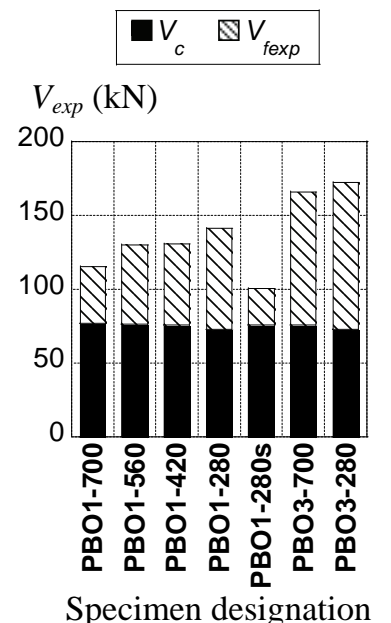

Specimen designation

presented in Fig. 11.

The results of specimens in Series I obviously revealed that the shear capacity and the shear carried by the internal mesh could be increased with the increase in the number of layers of the reinforcing PBO fiber mesh.

\section{c) Shear capacities in Series II}

In series II, the shear carried by the internal PBO fiber mesh significantly decreased with the increment of the width of PBO fiber mesh in the shear span, leading to the reduction of the total shear capacity of the specimens. The comparison of the shear capacities in Fig. 12 demonstrates that PBO1-280 shows the greatest shear capacity among the beams in which one layer of the internal mesh is provided and it is greater than the shear capacity of PBO1-700 by about $22.2 \%$. When the mesh width is expanded to $420 \mathrm{~mm}$ and $560 \mathrm{~mm}$ in PBO1-420 and PBO1-560, the shear capacities are reduced and they are higher than that of PBO1-700 by about $12.9 \%$ and $12.7 \%$, respectively. In addition, the shear carried by the mesh increases by about $77.5 \%$ in PBO1-280, $42.0 \%$ in PBO1-420, and $38.9 \%$ in PBO1-560 when compared with the shear carried by the mesh of PBO1-700.

From the results, it can be said that the highest efficiency of this reinforcing methodology can be obtained by using the appropriate width of the PBO fiber mesh, not the largest width of the mesh. The reason for this phenomenon will be discussed again in this paper. The results from PBO3-700 and PBO3-280 also showed the same trend as that of the specimens with one layer of PBO mesh. The shear capacity of PBO3-280 was higher than that of PBO3-700 by about 3.8\% and the shear carried by PBO fiber meshes of PBO3-280 was higher than that of PBO3-700 by about $10.7 \%$. 


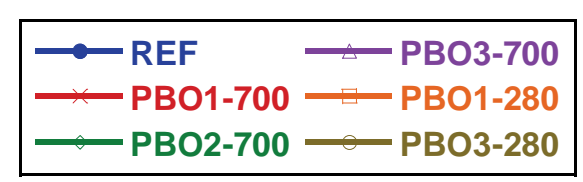

Load $(\mathrm{kN})$

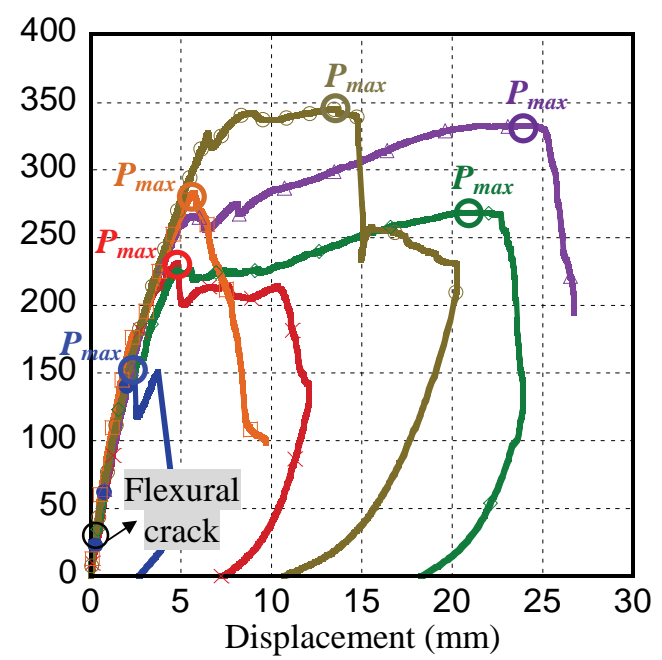

Fig. 13 Load-displacement curves in series I.
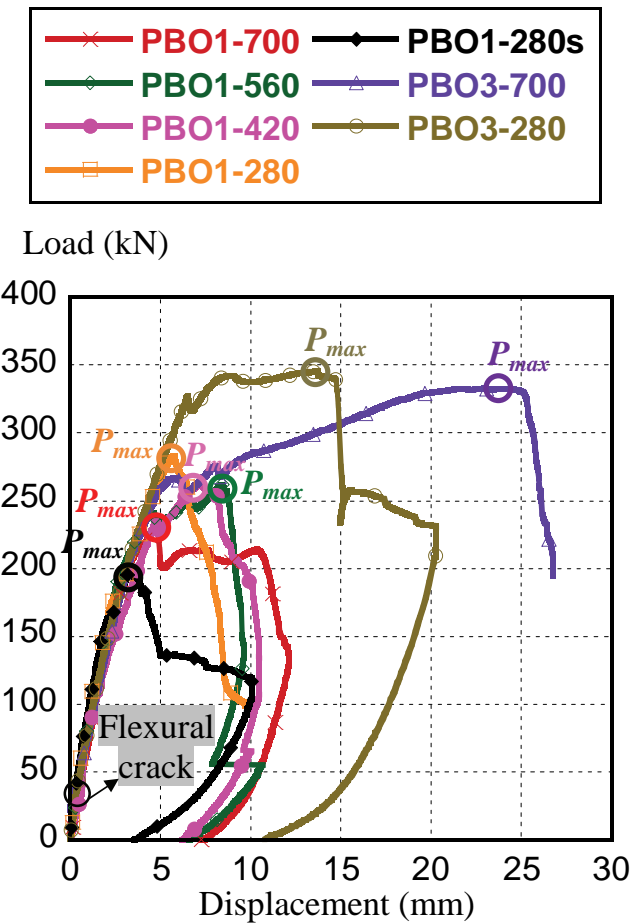

Fig. 14 Load-displacement curves in series II and III.

\section{d) Shear capacities in Series III}

As presented in Fig. 12, with the same amount of internal reinforcing $\mathrm{PBO}$ fiber mesh between PBO1-280 and PBO1-280s, the shear capacity and the shear carried by the internal PBO fiber mesh of PBO1-280 were greater than those of PBO1-280s by about $40.7 \%$ and $178.5 \%$, respectively. This implied that the reinforcing configuration powerfully impacted the capability of internal reinforcing PBO fiber mesh. The separation of the mesh in PBO1-280s may lead to a reduction of the reinforcing efficiency and the mesh which was not used to reinforce the center of the shear span may exhibit a lower performance than that of the mesh reinforcement at the center like PBO1-280 because the initiation of the diagonal crack of RC beams having shear span effective depth ratio $(a / d)$ higher than 2.5 usually occurred at around the center of the shear span.

\section{(2) Load-displacement relationships and crack development in RC beam test}

Figure 13 presents the relationships between the applied load and the mid-span displacement in Series I while the relationships of Series II and Series III are presented in Fig. 14.

The relationship of the REF beam exhibited the same behavior as that of a general RC beam without shear reinforcement in which the flexural crack initiated at the load about $30 \mathrm{kN}$ (data from the $50 \mathrm{~mm}$ $\pi$-gauges) leading to a small inclination of the curve. After that, the load gradually increased until the diagonal crack was observed as shown in Fig. 15 and the load reached its peak at $155.7 \mathrm{kN}$.

For the reinforced specimens, the applied load and displacement relationships had a similar behavior as that of the REF beam at the beginning; however, the failure pattern and the crack development were different after the diagonal crack happening. The development of cracks is explained by showing the crack propagation of PBO2-700 as a representative of all reinforced beams as presented in Fig. 16.

The first flexural crack of the reinforced specimens happened at approximately the same level as that of the REF beam. Then, the load of PBO2-700 in Fig. 13 still increased until the diagonal crack was introduced at the middle height of shear span as shown in Fig. 16(a). After that, the load still continuously increased because of the internal mesh, until the sudden horizontal crack occured at the area where concrete and the internal mesh were connected as clearly seen in Fig. 16(b). In fact, the horizontal crack was found in all reinforced specimens in this study except PBO1-280 and PBO1-280s as can be seen from the crack patterns at the peak load of all tested specimens in Fig. 15.

For all reinforced specimens except PBO1-280 and PBO1-280s, after the horizontal crack occurred, the progression of the load was distinctly slow with much extension in displacement especially in the specimens with a great amount of number of mesh layers. Finally, both diagonal crack and horizontal crack became seriously bigger as shown in Fig. 16(c) and then the loads reached their peak due to the rupture of the mesh in some portions. 


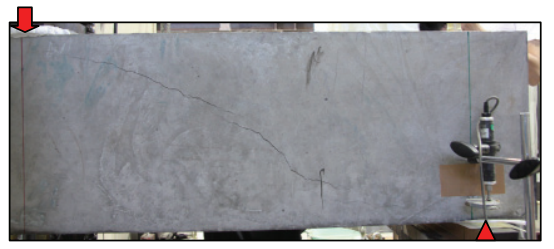

(a) REF

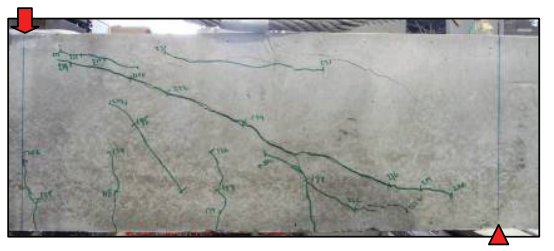

(d) PBO1-700

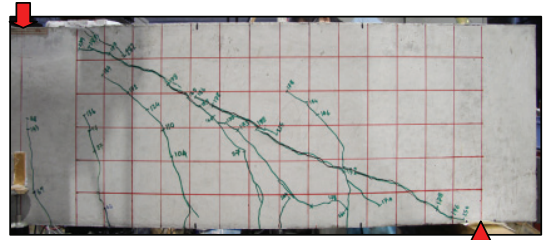

(g) PBO1-280

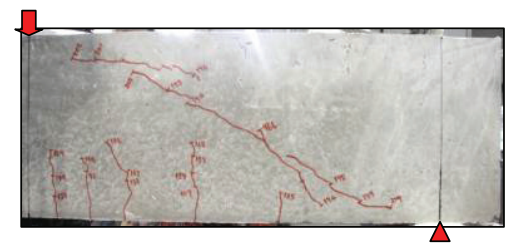

(a) Propagation of shear cracks

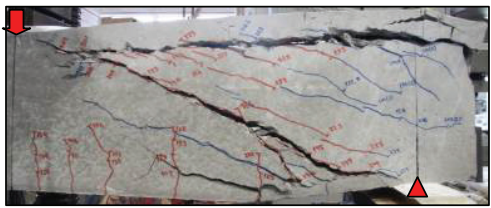

(c) Peak load

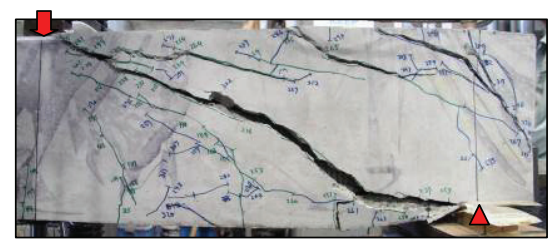

(b) $\mathrm{PBO}-700$

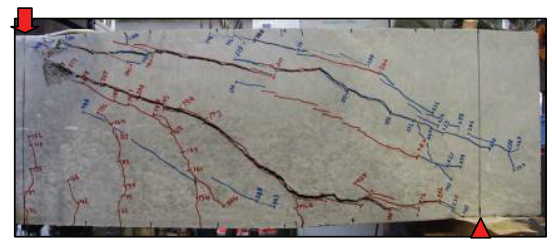

(e) PBO1-560

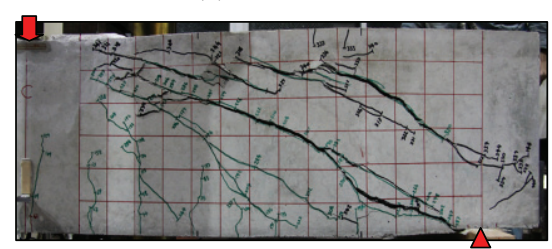

(h) PBO3-280

Fig. 15 Crack patterns (at peak load).

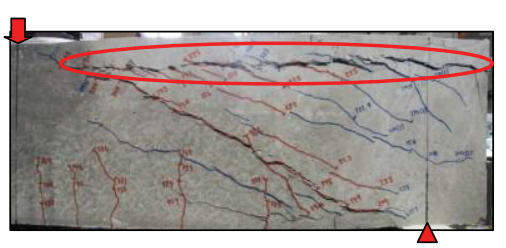

(b) Horizontal crack

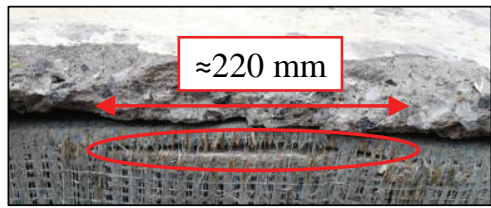

(d) Rupture of the internal meshes

Fig. 16 Crack development of PBO2-700.

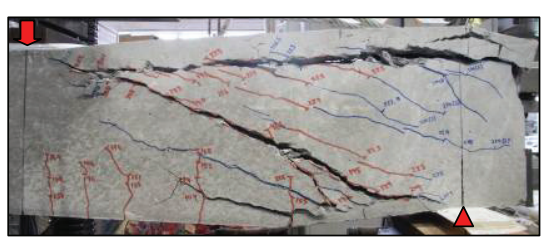

(c) PBO2-700

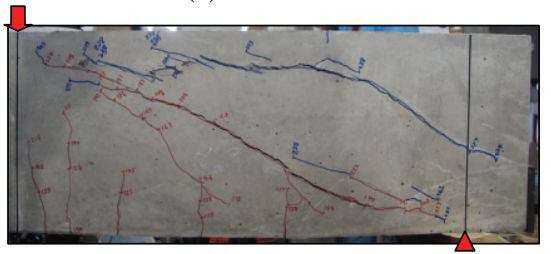

(f) PBO1-420

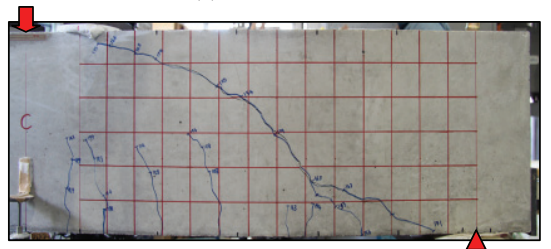

(i) PBO1-280s

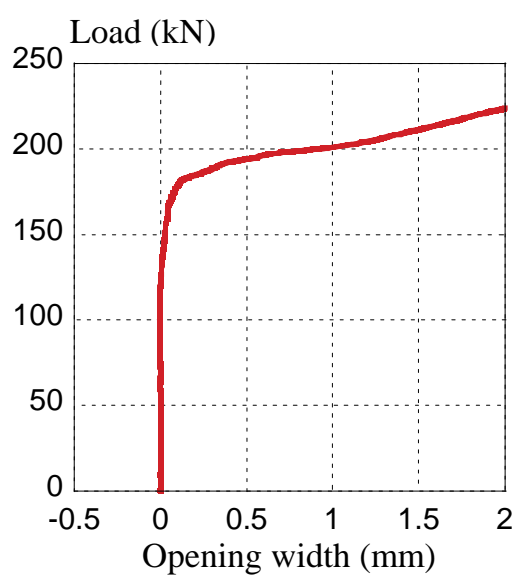

Fig. 17 Load-opening width at the middle height of shear span of PBO2-700.
It is essential to note that the yielding of tensile reinforcing bars was not observed in any specimen of this study.

\section{(3) Shear resisting mechanism in $\mathrm{RC}$ beam test}

Figure 17 shows the relationship between the load and opening crack width which was obtained from the $100 \mathrm{~mm} \pi$-gauge attached at the middle height of the shear span (as shown in Fig. 10) in PBO2-700. It can be described that the onset of the diagonal crack began at the load around 150-160 kN which corresponded to the peak load of the REF beam. Hence, it means that the shear carried by the internal PBO fiber mesh displayed the performance after the occurrence of a diagonal crack and this assumption was similar to the utilization of the conventional stirrups.

As mentioned before, the horizontal crack occurring after the propagation of the shear crack was observed in all reinforced specimens except
PBO1-280 and PBO1-280s. It was anticipated that the horizontal crack would occur because of the weak bond between concrete and the internal mesh since the filling concrete could not penetrate perfectly into the holes of the mesh. Therefore, the larger mesh greatly interrupted the connection of the concrete and this was the reason why the shear capacity of the beams was reduced even if the width of the reinforcing mesh was enlarged in Series II. In addition, this might be the reason why a horizontal crack was not found in PBO1-280 and PBO1-280s, since there was only one mesh layer and the width of the mesh was quite narrow compared with the other specimens.

After that, the interface between concrete cover and the reinforcing mesh of the specimens with horizontal crack was separated and then the tested specimen behaved like a beam whose cross-section was core portion and the PBO fiber mesh embraced 


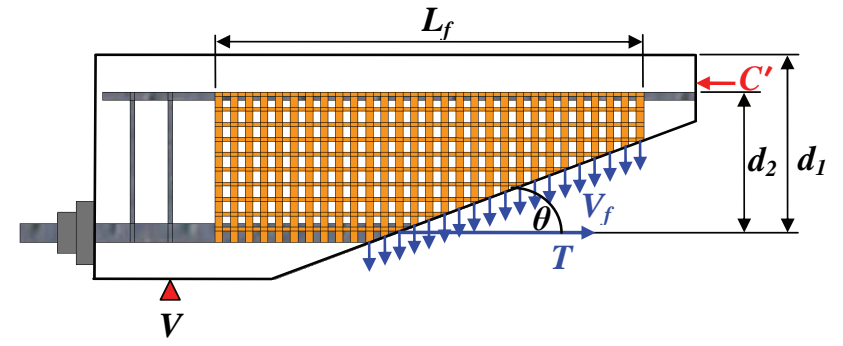

Fig. 18 Free-body diagram of RC beams strengthened with internal PBO fiber mesh.

it. The loose concrete cover led to the extension of displacement in the next stage and this also led to wider cracks both diagonally and horizontally. Some parts of the reinforcing mesh were then elongated until they almost reached their ultimate tensile strength. Finally, the sound of a rupture of the mesh was heard and then the load reached the peak. The rupture of the mesh was confirmed again by opening the specimens after the test. However, it was noticed that only some parts of the internal PBO fiber mesh (about $220 \mathrm{~mm}$ ) were ruptured as seen in Fig. 16(d).

\section{MODELING OF SHEAR CARRIED BY INTERNAL PBO FIBER MESH}

\section{(1) Calculation method for shear carried by in- ternal PBO fiber mesh}

The equation for evaluating shear carried by internal PBO fiber mesh was formulated based on the experimental results of seven reinforced specimens in this study: PBO1-700, PBO2-700, PBO3-700, PBO1-560, PBO1-420, PBO1-280, and PBO3-280. Note that PBO1-280s was not included in the empirical equation since the effect of reinforcing configuration had not been considered in the equation yet and this topic needed more study in the future.

By focusing on the force acting at the diagonal crack of RC beams reinforced with the internal PBO fiber mesh as shown in Fig. 18, the vertical tensile components are the contribution of shear carried by internal PBO fiber mesh $\left(V_{\text {fcal }}\right)$. The calculation method of $V_{\text {fcal }}$ can be derived from the $45^{\circ}$ truss analogy considering the ultimate tensile strength of the reinforcing mesh multiplied by the shear reinforcing efficiency of PBO mesh $\left(K_{P B O}\right)$ as follows:

$$
\begin{gathered}
V_{f c a l}=K_{P B O} \cdot\left(A_{f} \cdot f_{f u} \cdot z / s\right) \\
K_{P B O}=\left(-3.25 L_{f} / s+3.94\right) \cdot\left(-555.25 \rho_{P B O}+1.15\right)
\end{gathered}
$$

where, $A_{f}$ is the total cross-sectional area of PBO fiber mesh in the length $s\left(\mathrm{~mm}^{2}\right)\left[A_{f}=2 \cdot t_{f} \cdot l_{f} \cdot\right.$ (number of PBO fiber mesh strips according to Table 4)

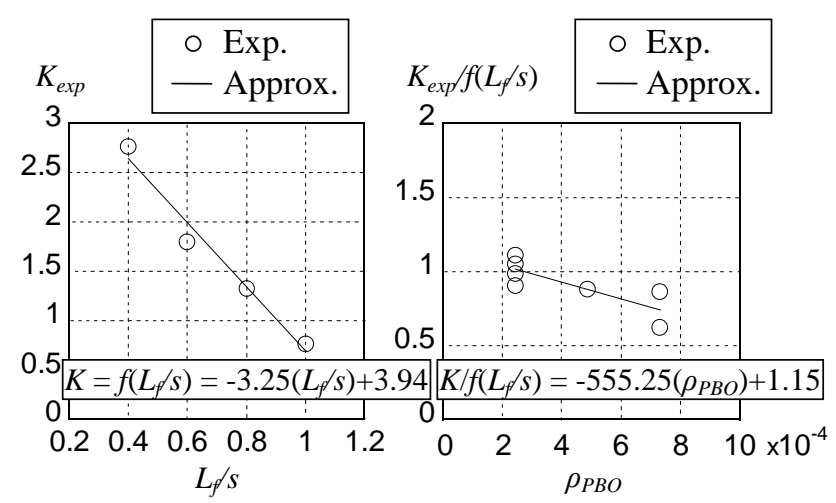

Fig. 19 Effect of $L_{f} / s$ on $K$.

Fig. 20 Effect of $\rho_{P B O}$ on $K$.

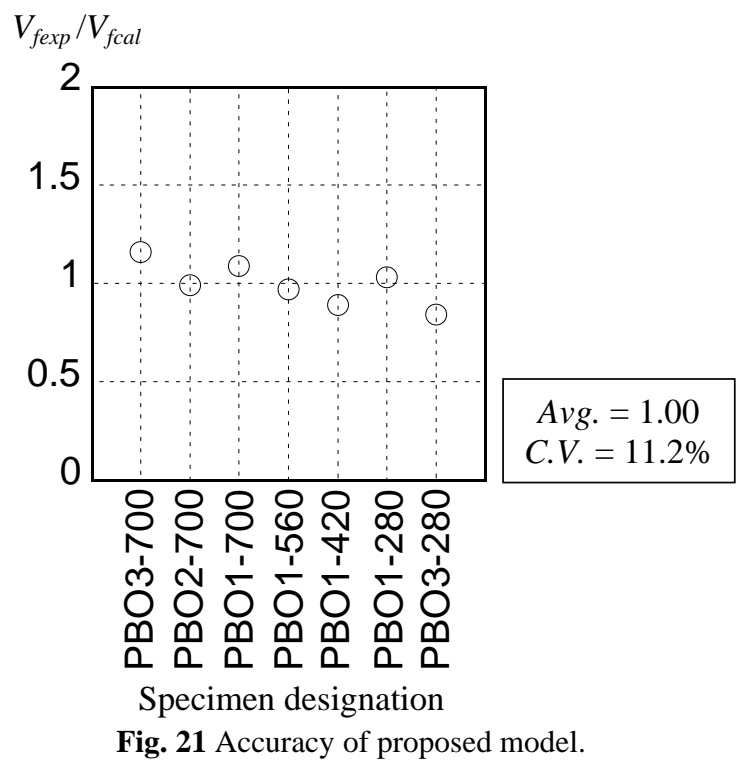

where $t_{f}$ and $l_{f}$ are the fiber thickness and the fiber width for one strip of the mesh], $f_{f u}$ is the ultimate tensile strength of PBO fiber mesh $\left(\mathrm{N} / \mathrm{mm}^{2}\right), z$ is the distance between the horizontal compression and tension members $(\mathrm{mm})[z=(7 / 8) d], s$ is the concerned length $[s=$ shear span $=700 \mathrm{~mm}]$, and $\rho_{P B O}$ is the PBO fiber mesh reinforcement ratio within the reinforcing mesh width $\left[\rho_{P B O}=A_{f} /\left(b_{w} \cdot L_{f}\right)\right]$.

The shear reinforcing efficiency $\left(K_{P в O}\right)$ was obtained from the relationships between the experimentally observed $K\left(K_{\text {exp }}\right)$ and its two affecting parameters. One was the ratio of mesh width to the concerned length $\left(L_{f} / s\right)$ as shown in Fig. 19. The other was the PBO fiber mesh reinforcement ratio within the mesh width $\left(\rho_{Р в O}\right)$ as shown in Fig. 20. The experimentally observed $K\left(K_{\text {exp }}\right)$ was calculated from the ratio of the experimental values $\left(V_{\text {fexp }}\right)$ and the ultimate capacity of reinforcing PBO fiber mesh from the $45^{\circ}$ truss analogy method.

Since the horizontal crack due to the separation of concrete and the internal reinforcing mesh had induced the beams to behave like their cross-section was only core portion as explained before, it is reasonable to consider the reduction of the distance 
Table 6 Comparison of experimental values $\left(V_{\text {fexp }}\right)$ with calculated values $\left(V_{\text {fcal }}\right)$ and JSCE values for externally bonded CFRP sheets.

\begin{tabular}{c|c|c|c|c|c|c|c|c|c|c|c|c|c|c|c|c}
\hline $\begin{array}{c}\text { Specimen } \\
\text { designation }\end{array}$ & $\begin{array}{c}A_{f} \\
\left(\mathrm{~mm}^{2}\right)\end{array}$ & $\begin{array}{c}f_{f u} \\
\left(\mathrm{~N} / \mathrm{mm}^{2}\right)\end{array}$ & $\begin{array}{c}d \\
(\mathrm{~mm})\end{array}$ & $\begin{array}{c}s \\
(\mathrm{~mm})\end{array}$ & $\begin{array}{c}L_{f} \\
(\mathrm{~mm})\end{array}$ & $\begin{array}{c}\rho_{P B O} \\
\left(10^{-4}\right)\end{array}$ & $\begin{array}{c}K_{P B O} \\
\mathrm{Eq.}(6)\end{array}$ & $\begin{array}{c}V_{\text {fcal }} \\
(\mathrm{kN})\end{array}$ & $\begin{array}{c}V_{\text {fexp }} \\
(\mathrm{kN})\end{array}$ & $\begin{array}{c}V_{\text {fexp }} \\
N_{\text {fcal }}\end{array}$ & $\begin{array}{c}s_{f} \\
(\mathrm{~mm})\end{array}$ & $\begin{array}{c}\rho_{f} \\
\left(10^{-4}\right)\end{array}$ & $\begin{array}{c}f_{c d}^{\prime} \\
(\mathrm{N} / \\
\left.\mathrm{mm}^{2}\right)\end{array}$ & $\begin{array}{c}E_{f} \\
(\mathrm{kN} / \\
\left.\mathrm{mm}^{2}\right)\end{array}$ & $\begin{array}{c}R \\
R\end{array}$ & $\begin{array}{c}K_{C F R P} \\
\mathrm{Eq.}(8)\end{array}$ \\
\hline PBO3-700 & 102.4 & 5800 & 205 & 700 & 700 & 7.31 & 0.51 & 77.6 & 90.1 & 1.16 & 700 & 7.31 & 38.9 & 240 & 1.27 & 0.83 \\
\hline PBO2-700 & 68.3 & 5800 & 205 & 700 & 700 & 4.88 & 0.61 & 61.9 & 61.5 & 0.99 & 700 & 4.88 & 33.8 & 240 & 1.20 & 0.88 \\
\hline PBO1-700 & 34.1 & 5800 & 205 & 700 & 700 & 2.44 & 0.70 & 35.5 & 38.6 & 1.09 & 700 & 2.44 & 40.3 & 240 & 0.95 & 1.04 \\
\hline PBO1-560 & 27.3 & 5800 & 205 & 700 & 560 & 2.44 & 1.36 & 55.2 & 53.6 & 0.97 & 700 & 1.95 & 39.8 & 240 & 0.90 & 1.07 \\
\hline PBO1-420 & 20.5 & 5800 & 205 & 700 & 420 & 2.44 & 2.02 & 61.5 & 54.8 & 0.89 & 700 & 1.46 & 38.3 & 240 & 0.85 & 1.11 \\
\hline PBO1-280 & 13.7 & 5800 & 250 & 700 & 280 & 2.44 & 2.68 & 66.3 & 68.5 & 1.03 & 700 & 0.98 & 34.0 & 240 & 0.80 & 1.14 \\
\hline PBO3-280 & 41.0 & 5800 & 205 & 700 & 280 & 7.31 & 1.96 & 119.7 & 99.7 & 0.84 & 700 & 2.93 & 34.2 & 240 & 1.05 & 0.98 \\
\hline
\end{tabular}

between the horizontal compression and tension members $(z)$ in the calculation of shear carried by internal mesh $\left(V_{\text {fcal }}\right)$. In the specimens having horizontal crack, the effective depth was the distance from the top of the reinforcing mesh to tension members $(d=205 \mathrm{~mm})$ as seen from $d_{2}$ in Fig. 18. On the other hand, the effective depth of PBO1-280 was from the top of the specimen to tension members $(d=250 \mathrm{~mm})$ as seen from $d_{1}$ in Fig. 18, since the horizontal crack was not found in this beam.

On the basis of this performed experiment, the empirical models may be exclusively applicable for the internal shear reinforcement by PBO fiber mesh. The shear reinforcing efficiency $\left(K_{P B O}\right)$ reported in this paper is particular for $L_{f} / s$ and $\rho_{P B O}$ that were used in this research. Careful assessment of mechanical properties of the members with different reinforcing condition is therefore recommended.

\section{(2) Comparison of calculated values and experi- mental values}

The comparison between the experimental values of shear carried by PBO fiber mesh $\left(V_{\text {fexp }}\right)$ obtained from Eq. (4) and the calculated values of shear carried by PBO fiber mesh ( $\left.V_{\text {fcal }}\right)$ obtained from Eqs. (5) and (6) is presented in Table 6. The accuracy of the proposed model is compared as shown in Fig. 21. The average (avg.) and the coefficient of variation (C.V.) of the ratio of the experimental value to the calculated value were $1.00 \%$ and $11.2 \%$, respectively.

It was demonstrated that a moderate agreement between calculated values and experimental values was obtained and this indicated that the model was capable of evaluating shear carried by internal reinforcing PBO fiber mesh.

Nevertheless, the reliability of the proposed model needs to be improved in the future since this new reinforcing method is quite new and the number of tested specimens is comparatively limited.
(3) Comparison of strengthening efficiency between internal PBO fiber mesh and externally bonded CFRP sheets

Unlike the conventional stirrups, the externally bonded FRP system and the proposed method by the internal PBO mesh exhibited a remarkable reduction in the strengthening performance of their systems. In the contribution of shear carried by the fiber of these two systems, the ultimate tensile strength of the FRP material has to be multiplied by the shear reinforcing efficiency $(K)$.

The calculation method from JSCE ${ }^{4)}$ for predicting shear carried by the externally bonded CFRP sheet described in Eqs. (7) and (8) were taken to compare the strengthening efficiency with the shear carried by the internal PBO fiber mesh in this study. Even the purpose of applying these two systems is different because the former is for strengthening existing structures, while the latter is for reinforcing new structures. The comparison can represent the possibility of the applicability of the existing design method for the external system to the internal system. Moreover, the comparison may imply whether this new proposed internal system by PBO mesh is worthwhile applying to the real structures or not.

Assuming that RC beams were strengthened with externally bonded high-strength type of carbon fiber sheets with the same reinforcement ratio, same compressive strength of concrete, and same size of RC beams as the experiments in this study, the summary of the calculation from JSCE recommendations $^{4}$ can be seen in Table 6. It is noted that the mechanical properties of the continuous carbon fiber sheets can be considered by using the general values of the high-strength type of carbon fiber sheets in which the tensile strength is $4100 \mathrm{~N} / \mathrm{mm}^{2}$ and the modulus of elasticity is $240 \mathrm{kN} / \mathrm{mm}^{2}$.

$$
\begin{gathered}
V_{f d}=K_{C F R P} \cdot\left\lfloor A_{f} \cdot f_{\text {fud }}\left(\sin \alpha_{f}+\cos \alpha_{f}\right) / s_{f}\right\rfloor \cdot z \\
K_{C F R P}=1.68-0.67 R
\end{gathered}
$$




$$
\begin{gathered}
R=\left(\rho_{f} \cdot E_{f}\right)^{1 / 4}\left(\frac{f_{f u d}}{E_{f}}\right)^{2 / 3}\left(\frac{1}{f^{\prime} c d}\right)^{1 / 3} ; 0.5 \leq R \leq 2.0 \\
\rho_{f}=A_{f} /\left(b_{w} \cdot s_{f}\right)
\end{gathered}
$$

where, $K_{C F R P}$ is the shear reinforcing efficiency of continuous fiber sheets, $A_{f}$ is the total cross-sectional area of continuous fiber sheets in space $s_{f}\left(\mathrm{~mm}^{2}\right), s_{f}$ is the spacing of continuous fiber sheet $(\mathrm{mm}), f_{\text {fud }}$ is the design tensile strength of continuous fiber sheet $\left(\mathrm{N} / \mathrm{mm}^{2}\right), E_{f}$ is the modulus of elasticity of continuous fiber sheet $\left(\mathrm{kN} / \mathrm{mm}^{2}\right), f_{c d}^{\prime}$ is the compressive strength of concrete $\left(\mathrm{N} / \mathrm{mm}^{2}\right), \alpha_{f}$ is the angle formed by continuous fiber sheet about the member axis, and $z$ is the distance between the horizontal compression and tension members (mm).

The comparison of the reinforcing efficiency between $K_{C F R P}$ from Eq. (8) and $K_{P B O}$ from Eq. (6) revealed that the efficiency of the externally bonded CFRP system was higher than that of the internal reinforcing PBO system when the reinforcing materials were provided for the whole shear span as shown in PBO3-700, PBO2-700, and PBO1-700 in Table 6. However, $K_{C F R P}$ became lower than $K_{P B O}$ when the width of the reinforcing materials in the shear span was reduced similar to what was done in PBO1-560, PBO1-420, PBO1-280, and PBO3-280.

The authors believe that it is unfair to conclude that the reinforcing efficiency of the internal mesh system is higher than that of the external FRP system when the width of reinforcing materials is limited, since the JSCE recommendations ${ }^{4)}$ have not yet considered the effect of width of reinforcing materials. In addition, from the results of the strain distribution in FRP along critical shear crack of Cao et al. $2005^{12)}$, there is a possibility that the actual reinforcing efficiency of the externally bonded FRP system may be larger with shorter FRP sheets because the highest FRP strain is always displayed at about the center of the shear span. Therefore, the utilization of reinforcing materials close to the two ends of the shear crack may be comparatively meaningless.

Another way to estimate the reinforcing efficiency of the externally bonded CFRP system in the case of the specimens with limited width of CFRP sheets is to assume that the shear carried by CFRP sheets in the case of full shear span strengthening (PBO1-700 and PBO3-700) and is the same as in the case of limited shear span strengthening (PBO1-560, PBO1-420, PBO1-280, and PBO3-280). Then, the reinforcing efficiency of the specimens whose width of CFRP sheets is limited $\left(K_{C F R P 2}\right)$ can be derived as follows:

$$
\begin{aligned}
& \left.V_{f d 1}=K_{C F R P 1} \cdot \mid A_{f 1} \cdot f_{f u d}\left(\sin \alpha_{f}+\cos \alpha_{f}\right) / s_{f}\right] \cdot z \\
& \begin{array}{l}
\left.V_{f d 2}=K_{C F R P 2} \cdot \mid A_{f 2} \cdot f_{f u d}\left(\sin \alpha_{f}+\cos \alpha_{f}\right) / s_{f}\right] \cdot z \\
\text { Assuming } \quad V_{f d 1}=V_{f d 2} \\
\text { then } \quad K_{C F R P 2}=\left(A_{f 1} / A_{f 2}\right) \cdot K_{C F R P 1}
\end{array}
\end{aligned}
$$

where, $V_{f d 1}$ is the shear carried by CFRP sheets in the case of full shear span strengthening, $V_{f d 2}$ is the shear carried by CFRP sheets in the case of limited shear span strengthening, $K_{C F R P 1}$ is the shear reinforcing efficiency of CFRP sheets in the case of full shear span strengthening (from Eq.(8)), $K_{C F R P 2}$ is the shear reinforcing efficiency of CFRP sheets in the case of limited shear span strengthening, $A_{f 1}$ is the total cross-sectional area of CFRP sheets in space $s_{f}$ in the case of full shear span strengthening, and $A_{f 2}$ is the total cross-sectional area of CFRP sheets in space $s_{f}$ in the case of limited shear span strengthening (from Table 6).

By following this assumption and ignoring the slight difference in $f^{\prime}{ }_{c d}$ of each specimen the reinforcing efficiency $\left(K_{C F R P}\right)$ becomes 1.30 for PBO1-560, 1.73 for PBO1-420, 2.60 for PBO1-280 and 2.08 for PBO3-280. Different from the values calculated from Eq. (8), the $K_{C F R P}$ demonstrates slightly higher values than that of the internal PBO fiber mesh system. The comparison implies that the internal PBO fiber mesh reinforcing system may display almost the same strengthening efficiency as the conventional externally bonded FRP sheets system when the width of strengthening materials is limited.

It must be noted that the results of $K_{C F R P 2}$ from Eq. (14) may be moderately overestimated since the shears carried by CFRP sheets in the case of full-wrapped beams and the limited-wrapped beams are assumed to be same as shown in Eq. (13), however, $K_{P B O}$ in Table 6 and the overvalued $K_{C F R P 2}$ are still quite comparable. This indicates that the internal PBO reinforcing system proposed in this study is reasonably productive.

\section{CONCLUSIONS}

(1) The internally reinforcing PBO fiber mesh from the elementary test demonstrated its performance to be at the same level as its tensile strength especially the mesh that was coated with epoxy resin before casting concrete, indicating that the internal PBO fiber mesh can be applied for reinforcing bigger concrete structural members.

(2) A new method for reinforcing concrete beam by using the internal PBO fiber mesh is proven to 
enhance the shear performance of the reinforced specimens. The internal reinforcing mesh exhibited its performance after the occurance of a diagonal crack.

(3) Increasing the number of internal PBO fiber mesh layers led to the increase in shear capacity and shear carried by reinforcing mesh. Besides, the reinforcing mesh that was provided at the center of the shear span showed better shear resisting performance than that of the non-centered one.

(4) The internal reinforcing system by PBO fiber mesh may impair the integrity of concrete. The highest reinforcing efficiency of this method can be obtained by using the proper width of the mesh, not the largest width of the mesh.

(5) The proposed model by using the $45^{\circ}$ truss analogy method was reasonable for evaluating the shear carried by internal PBO fiber mesh. The average of the ratio between experimental values and calculated values was 1.00 and the coefficient of variation was equal to $11.2 \%$.

(6) The comparison of the reinforcing efficiency between the internal PBO fiber mesh and the externally bonded CFRP sheet based on the $45^{\circ}$ truss analogy showed that the efficiency of the externally bonded system was higher than that of the internal mesh system when the reinforcing materials were fully provided for the whole shear span. However, when the width of reinforcing material was limited in the shear span, the difference in the reinforcing efficiency of both systems was very slight.

ACKNOWLEDGMENT: The authors would like to acknowledge Neturen Co., Ltd. for providing the deformed high-strength reinforcing bars used in this study.

\section{REFERENCES}

1) Khalifa, A. and Nanni, A. : Improving shear capacity of existing RC T-section beams using CFRP composites, Cement \& Concrete Composites, Vol. 22, pp. 165-174,
2000.

2) Zhang, Z. and Hsu, C. : Shear strengthening of reinforced concrete beams using carbon fiber reinforced polymer laminates, Journal of Composites for Construction, Vol. 9, No. 2, pp. 158-169, 2005.

3) Saafan, M. A. A. : Shear strengthening of reinforced concrete beams using GFRP wraps, Acta Polytech, Vol. 46, No. 1, pp. 24-32, 2006.

4) Research committee on upgrading of concrete structures with use of continuous fiber sheet : Recommendations for upgrading of concrete structures with use of continuous fiber sheets, Concrete Engineering Series, No. 41, JSCE, Tokyo, 2001.

5) Wu, Z. S., Iwashita, K., Hayashi, K., Higuchi, T., Murakami, S. and Koseki, Y. : Strengthening PC structures with externally prestressed PBO fiber sheets, Proceedings of the International Conference on FRP Composites in Civil Engineering, CICE2001 (J. Teng (ed.)), Elsevier Science, Oxford, pp. 1085-1092, 2001.

6) Ombres, L. : Structural performances of PBO FRCM-strengthened RC beams, Proceedings of the Institution of Civil Engineers (ICE), Structures \& Buildings, Vol. 164, No. SB4, pp. 265-272, 2011.

7) Ombres, L. : Flexural analysis of reinforced concrete beams strengthened with a cement-based high-strength composite material, Journal of Composite Structures, Vol. 94, No. 1, pp. 143-155, 2011.

8) Di Tommaso, A., Focacci, F., Mantegazza, G. and Gatti, A. : FRCM versus FRP composites to strengthen RC beams: a comparative analysis, Proceedings of the International Symposium on Fiber Reinforced Polymers Reinforced Concrete Structures (FRPRCS-8), Patras, Greece, 2007.

9) $\mathrm{Li}, \mathrm{H}$. and $\mathrm{Xu}, \mathrm{S}$. : Self-compacting concrete for textile-reinforced elements, First International Symposium on Design, Performance and Use of Self-Consolidating Concrete (SCC'2005), Changsha, Hunan, China, 2005.

10) Ruredil, S. P. A. : X Mesh Gold - Technical data sheet, S. Donato Milanese, Milan, Italy, 2006.

11) Niwa, J., Yamada, K., Yokozawa, K. and Okamura, H. : Revaluation of the equation for shear strength of reinforced concrete beams without web reinforcement, Concrete Library of JSCE, No. 9, 1987.

12) Cao, S. Y., Chen, J. F., Teng, J. G., Hao, Z. and Chen, J. : Debonding in RC beams shear strengthened with complete FRP wraps, Journal of Composites for Construction, Vol. 9, No. 5, pp. 417-428, 2005.

(Received June 5, 2014) 